\title{
Ion-Molecule Reactions of Oxygenated Chemical Ionization Reagents with Vincamine
}

\author{
Gerald F. Bauerle, Jr., Brad J. Hall, Ngoc V. Tran, and Jennifer S. Brodbelt \\ University of Texas at Austin, Department of Chemistry, Austin, Texas, USA
}

\begin{abstract}
The ion-molecule reactions of ions from acetone, dimethyl ether, 2-methoxyethanol, and vinyl methyl ether with vincamine were investigated. Reactions with dimethyl ether result in $[M+13]^{+}$and $[M+45]^{+}$products, reactions with 2-methoxyethanol produce $[M+13]^{+}$ and $[\mathrm{M}+89]^{+}$ions, and reactions with acetone or vinyl methyl ether ions generate predominantly $[M+43]^{+}$ions. Collision-activated dissociation and deuterium labeling experiments allowed speculation about the product structures and mechanisms of dissociation. The methylene substitution process was shown to occur at the hydroxyl oxygen and the phenyl ring of vincamine for dimethyl ether reactions, but the methylene substitution process was not favored at the hydroxyl oxygen for the 2-methoxyethanol reactions, instead favored at the 12 phenyl position. The reaction site is likely different for the 2-methoxyethanol ion due to its capability for secondary hydrogen-bonding interactions. For the $[M+45]^{+}$and $[\mathrm{M}+89]^{+}$ions, evidence suggests that charge-remote fragmentation processes occur from these products. In general, the use of dimethyl ether ions or 2-methoxyethanol ions for ionmolecule reactions prove highly diagnostic for the characterization of vincamine; both molecular weight and structural information are obtained. Limits of detection for vincamine with dimethyl ether chemical ionization via this technique on a benchtop ion trap gas chromatography-tandem mass spectrometer are in the upper parts per trillion range. (J Am Soc Mass Spectrom 1996, 7, 250-260)
\end{abstract}

$\mathrm{V}$ incamine is an alkaloid found in the Apocynaceae family of plants that has medicinal uses as a vasodilator [1] (see Figure 1). Analysis of this compound most commonly has been accomplished by high-performance liquid chromatography techniques by using UV [2-8], voltammetric [9], or thermospray mass spectrometry [10] as the detection technique. Thin-layer chromatography (TLC) combined with UV reflectance spectroscopy [11] and countercurrent chromatography with thermospray mass spectrometry [12] are other techriques that also have been used to analyze vincamine. Gas chromatography (GC) analysis has been performed on both derivatized $[13,14]$ and nonderivatized forms of vincamine $[15,16]$ with flame ionization detector (FID) [13], nitrogen flame ionization detector (NFID) [15, 16], or selected ion electron ionization mass spectrometric detectors [14]. The electron ionization (EI) mass spectrum of vincamine has been studied in great detail [13, 17-19]. The EI mass spectrum of vincamine is suitable for identification of the compound, but at low concentrations the ion current is divided among many low mass fragment ions that may impact the limit of detection. No detailed analysis of the structure or fragmentation

Address reprint requests to Professor Jennifer S. Brodbelt, Department of Chemistry and Biochemistry, University of Texas at Austin Welch Hall 1.202, Austin, TX 78712-1167. pathways of the protonated species from thermospray mass spectrometry has been done. To our knowledge, chemical ionization reactions and analysis have not been performed either.

Because of our interest in the analytical utility of novel ion-molecule reactions in a quadrupole ion trap mass spectrometer, we decided to study the reactions and evaluate the effectiveness of four oxygenated chemical ionization reagents with vincamine. Many new CI reagents have been identified in the past decade [20], and several have been chosen for this study: acetone, dimethyl ether, 2-methoxyethanol, and vinyl methyl ether. Each has demonstrated previous analytical utility [20-30]. For example, reaction of monosaccharides with protonated acetone and its protonated dimer gives formation of $[M+41]^{+}$and $[M+59]^{+}$ ions [22], and the acetyl ion from acetone was found to undergo Diels-Alder cycloaddition reactions with isoprene [23]. The methoxymethylene cation $\left(\mathrm{CH}_{3} \mathrm{OCH}_{2}\right)^{+}$from dimethyl ether has been shown to react with double bonds [24] and to undergo selective reactions with oxyaromatic compounds [25-27]. Ion-molecule reactions of the methylene-substituted ion from 2-methoxyethanol have proven to be selective as a result of secondary hydrogen-bonding interactions, which provide exclusive selectivity for amines [21]. Vinyl methyl ether radical cations as well as the neutral species also have proven useful to determine the location of double bonds [28-30]. 
<smiles>CCC12CCCN3CCc4c(n(c5ccccc45)[C@](C)(C(=O)O)C1)C32</smiles><smiles>CCC12CCCN3CCCc4c(n(c5ccccc45)C(=O)C1)C32</smiles><smiles>COC(=O)C1C(O)CCC2CN3CCc4c([nH]c5ccccc45)C3CC2C1C</smiles>

Figure 1. Structures of vincamine, eburnamonine, and corynanthine.

In this report, the ion-molecule reactions of vincamine with reagent ions from acetone, dimethyl ether, 2-methoxyethanol, and vinyl methyl ether are evaluated in a quadrupole ion trap to compare the analytical merit of each chemical ionization reactant in terms of reaction efficiencies, structural information, product distribution, and diagnostic utility. Special attention is directed at comparison of the reactions of $\mathrm{CH}_{3} \mathrm{OCH}_{2}^{+}$ (from dimethyl ether) and $\mathrm{CH}_{3} \mathrm{OCH}_{2} \mathrm{CH}_{2} \mathrm{OCH}_{2}^{+}$(from 2-methoxyethanol) because of their homologous structures. Collision-activated dissociation was performed on selected products to probe their structures and to gain mechanistic insight. When possible, deuterated reagents were used for comparison. Finally, the utility of this method of analysis was tested on a benchtop gas chromatography-tandem mass spectrometry (GCMS/MS) ion trap system.

\section{Experimental}

Experiments were performed on a Finnigan MAT (San Jose, CA) ion trap mass spectrometer (ITMS) and a Varian (Walnut Creek, CA) Saturn 4D GC-MS/MS ion trap spectrometer. In the ITMS, reagents were introduced through heated leak valves or through needle valves to an uncorrected pressure of approximately $1 \times 10^{-5}$ torr. Vincamine was introduced through a direct-insertion solids probe heated to a temperature of $180-210^{\circ} \mathrm{C}$ and to an indicated pressure of $6 \times 10^{-6}$ torr. Helium was introduced through a needle valve and the pressure was nominally $9 \times 10^{-5}$ torr. The reagents were ionized by electron ionization for durations between 10 and $30 \mathrm{~ms}$, and selected ions were isolated by using the apex isolation technique. To obtain chemical ionization spectra, the reagent ions then were allowed to react with neutral vincamine for approximately $20 \mathrm{~ms}$, and the product ions were detected via the mass-selective instability mode. For collision-activated dissociation (CAD), reaction times were on the order of $200 \mathrm{~ms}$. After the reaction time, selected ions were isolated and an ac voltage of 300 to $500 \mathrm{mV}$ was applied across the endcap electrodes for a duration of 10 to $20 \mathrm{~ms}$ at a $q$ value of approximately 0.3. The manifold temperature was held constant at $120^{\circ} \mathrm{C}$ for all expcriments and all scans were averaged a minimum of 25 times before data were collected.

Vincamine was prepared for analysis in the Saturn 4D by derivatization. Then $1.1 \mathrm{mg}$ of vincamine was added to $0.10 \mathrm{~mL}$ of $99 \%$ bis(trimethylsilyl)trifluoroacetamide (BSTFA), 1\% trimethylchlorosilane (TCMS), and $0.10-\mathrm{mL}$ pyridine. The solution was then heated in a water bath for $5 \mathrm{~h}$ at approximately $70{ }^{\circ} \mathrm{C}$. This procedure resulted in derivatization of the hydroxyl group to a trimethyl silyl ether group. This volume was then diluted to $10 \mathrm{~mL}$ with dichloromethane, and serial dilutions were employed to obtain the desired concentration for injection.

Chemical ionization (CI) was performed on the Saturn 4D equipped with a septum-equipped programmable injector (SPI) in the selected ejection chemical ionization mode (SECI). Reagent ions were ionized for a variable duration set by the instrument's automatic reaction control (ARC) and were isolated by using a combination of a rf ramp and a multifrequency waveform. The reagent ions and the neutral vincamine-TMS derivative then were allowed to react for a duration set by the ARC. Mass-selective instability then was used to detect the ions. ARC parameters for dimethyl ether were as follows: $0.1-\mathrm{ms}$ ARC ionization time, 2.5-ms CI maximum ionization time, $128-\mathrm{ms} \mathrm{CI}$ maximum reaction time, $15-\mathrm{u} \mathrm{CI}$ ionization storage level, 8.0-V reagent ion eject amplitude, $40-\mathrm{u} \mathrm{CI}$ reaction storage level, and a $67-\mathrm{u}$ background mass. The autotune program was used to set most instrument parameters with the exception of the ARC target, which was set manually to 25,000 counts. The values for these parameters were a $25-\mu \mathrm{A}$ filament emission current and an electron multiplier voltage of $1700 \mathrm{~V}$. The manifold heater temperature was set to $240{ }^{\circ} \mathrm{C}$, and the axial modulation voltage was set to $4.0 \mathrm{~V}$. Pressures for dimethyl ether and helium were approximitely $1 \times 10^{-5}$ and $1 \times 10^{-3}$ torr, respectively. Three scans were averaged over a 1 -s duration with a mass range of 70-450 u. The autotune program also was used to establish optimized conditions for electron ionization conditions. For EI experiments, the emission current was set at $12 \mu \mathrm{A}$ and an AGC target of 65,100 counts.

A 30-m DB-5ms capillary column (J \& W Scientific, Folsom, CA) with a film thickness of $0.25 \mu \mathrm{m}$ and an internal diameter of $0.25 \mathrm{~mm}$ was used. The injector head pressure was held at $12 \mathrm{lb} /$ in. $^{2}$ and the transfer line temperature was $260^{\circ} \mathrm{C}$. A GC oven program was used that consisted of a $1.8-\mathrm{min}$ hold at $50{ }^{\circ} \mathrm{C}$, a $25-{ }^{\circ} \mathrm{C} / \mathrm{min}$ ramp to $280^{\circ} \mathrm{C}$, and a hold at $280^{\circ} \mathrm{C}$ until a total program time of $17 \mathrm{~min}$ was reached. The SPI 
program consisted of a 0.5 -min hold at $50{ }^{\circ} \mathrm{C}$ followed by a $180{ }^{\circ} \mathrm{C} / \mathrm{min}$ ramp to $280^{\circ} \mathrm{C}$, and a hold at $280^{\circ} \mathrm{C}$ until $17 \mathrm{~min}$ had elapsed from the injection. Splitless injections were performed by injection of $1-\mu \mathrm{L}$ samples into the SPI. The signals from the ions that gave the three largest intensities were summed to determine the limit of detection (LOD) for vincamine in the dimethyl ether SECI mode. Before each limit of detection run, blank runs of dichloromethane were performed to ensure that carryover from previous runs would not appear in the LOD run. The limit of detection was then confirmed by a retention time that matched to within 2 $s$ and by a signal-to-noise ratio of at least 5 .

Corynanthine, eburnamonine, 2-methoxyethanol, pyridine, and vincamine were obtained from Aldrich Chemical Co. (Milwaukee, WI). BSTFA and TCMS were obtained from Supelco, Inc. (Bellefonte, PA). Dimethyl ether was obtained from MG Industries (Valley Forge, PA). Perdeuterated dimethyl ether was obtained from Isotec (Miamisburg, $\mathrm{OH}$ ). Acetone was obtained from J.T. Baker, Co. (Phillipsburg, NJ). Vinyl methyl ether was obtained from Matheson Gas Products (East Rutherford, NJ). Perdeuterated acetone was obtained from Cambridge Isotope Labs, Inc. (Andover, MA). Dichloromethane was obtained from E.M. Science (Gibbstown, NJ). All compounds were used without further purification.

\section{Results and Discussion}

As described in detail hereafter, the ion-molecule reactions of the four reactants with vincamine were monitored in a quadrupole ion trap. The products are summarized in Table 1, and a combination of CAD, including $\mathrm{MS}^{3}$, and deuterium labeling experiments allowed speculation about the structures of the products and their mechanisms of formation.

\section{Dissociation of Protonated Vincamine}

Protonated vincamine is observed in the chemical ionization spectra that used dimethyl ether ions, acetone ions, or vinyl methyl ether ions. The three most predominant fragmentation pathways of protonated vincamine include dehydration, loss of $60 \mathrm{u}$ (net loss of $\mathrm{C}_{2} \mathrm{H}_{4} \mathrm{O}_{2}$ ), and formation of the ion at $212 \mathrm{u}$. The loss of $60 \mathrm{u}$ is proposed to be a consecutive elimination of methanol and CO. The loss of methanol alone is not observed in the CAD spectrum of protonated vincamine, and this observation suggests that the subsequent elimination of $\mathrm{CO}$ is facile and exothermic. Alternatively, the loss of $60 \mathrm{u}$ could be rationalized as a concerted loss of methyl formate that involves the ester portion of the vincamine structure. We have no experimental evidence to prove or disprove either mechanism. Collision-activated dissociation of protonated vincamine also promotes a loss of water that results in an ion at $337 \mathrm{u}$, the predominant fragment ion. Protonation on the pyrrole nitrogen followed by
Table 1. Chemical ionization reaction products

\begin{tabular}{|c|c|c|}
\hline $\begin{array}{l}\text { Reagent gas } \\
\text { (reactant ions) }\end{array}$ & Ions produced & Relative percent \\
\hline Acetone & {$[M+43]^{+}$} & 45 \\
\hline \multirow[t]{3}{*}{$(43)^{+}$} & {$\left[\mathrm{M}+43-\mathrm{H}_{2} \mathrm{O}\right]^{+}$} & $\leq 5$ \\
\hline & {$[\mathrm{M}+\mathrm{H}]^{+}$} & 20 \\
\hline & $337^{+}$ & 30 \\
\hline Dimethyl ether & {$[M+45]^{+}$} & 35 \\
\hline \multirow[t]{9}{*}{$\left(45^{+}, 47^{+}\right)$} & {$[M+13]^{+}$} & $\leq 5$ \\
\hline & {$[\mathrm{M}+\mathrm{H}]^{+}$} & $\leq 5$ \\
\hline & $\mathrm{M}^{+\cdot}$ & 10 \\
\hline & {$[M-H]^{+}$} & $\leq 5$ \\
\hline & $337^{+}$ & 20 \\
\hline & $277^{+}$ & 10 \\
\hline & $247^{+}$ & $\leq 5$ \\
\hline & $233^{+}$ & $\leq 5$ \\
\hline & $215^{+}$ & $\leq 5$ \\
\hline 2-Methoxyethanol & {$[M+89]^{+}$} & 15 \\
\hline \multirow[t]{3}{*}{$\left(89^{+}\right)$} & {$[M+13]^{+}$} & 70 \\
\hline & $168^{+}$ & 10 \\
\hline & $161^{+}$ & $\leq 5$ \\
\hline Vinyl methyl ether & {$[M+43]^{+}$} & 15 \\
\hline \multirow[t]{5}{*}{$\left(43^{+}\right)$} & {$\left[\mathrm{M}+43-\mathrm{H}_{2} \mathrm{O}\right]^{+}$} & $\leq 5$ \\
\hline & {$\left[\mathrm{M}+\mathrm{H}^{+}\right.$} & 20 \\
\hline & $\mathrm{M}^{+\cdot}$ & 10 \\
\hline & {$[\mathrm{M}-\mathrm{H}]^{+}$} & 10 \\
\hline & $337^{+}$ & 40 \\
\hline
\end{tabular}

intramolecular proton transfer to the hydroxyl oxygen is a reasonable explanation for the dehydration process.

\section{Reactions with Dimethyl Ether Ions}

Dimethyl ether has two predominant reactive cations after electron ionization: the methoxymethylene cation $\left(\mathrm{CH}_{3} \mathrm{OCH}_{2}\right)^{+}$at $45 \mathrm{u}$ and the protonated dimethyl ether cation $\left(\mathrm{CH}_{3} \mathrm{OCH}_{3}\right) \mathrm{H}^{+}$at $47 \mathrm{u}$. The methoxymethylene cation has been shown to either methylene substitute or methylate, dependent on several structural features of the analyte [24-27]. These features include the absence or presence of an acidic hydrogen, the presence of two interacting oxygen- or nitrogencontaining functional groups, and the nature of substituents on an aromatic ring [24-27]. Protonated dimethyl ether has demonstrated excellent protonating capabilities $[25,27]$. These two ions were isolated for the chemical ionization reaction.

The ion-molecule reactions of dimethyl ether ions with vincamine generated product ions with large intensities in a relatively short reaction time $(30 \mathrm{~ms})$. An example of the ion-molecule reaction product spectrum is shown in Figure 2, and these products are summarized in Table 1 . The product ion with the greatest intensity corresponds to adduct formation of the methoxymethylene ion with vincamine at $399 \mathrm{u}$ $\left([\mathrm{M}+45]^{+}\right)$. Other ions present include the methy- 


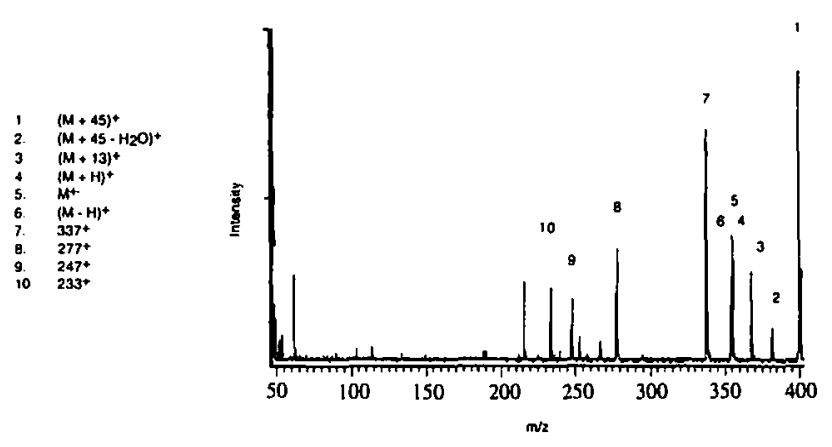

Figure 2. Chemical ionization products from the reaction of vincamine with dimethyl ether ions.

lene-substituted product at $367 \mathrm{u}\left([\mathrm{M}+13]^{+}\right)$, the protonated product at $355 \mathrm{u}\left([\mathrm{M}+\mathrm{H}]^{+}\right)$, and other lower mass ions. The formation of methylated vincamine $\left([\mathrm{M}+15]^{+}\right)$does not occur. These ions are characteristic of dimethyl ether reactions and lead to easy confirmation of the molecular weight of the compound by a series of well defined products.

The presence of the $[M+13]^{+}$ion at $367 u$ is indicative of methylene substitution at an activated site on the molecule. This product is known to arise from the elimination of methanol from the $[\mathrm{M}+45]^{+}$ precursor $[25,26]$, and has the net reaction $[\mathrm{M}+$ $\mathrm{CH}_{3} \mathrm{OCH}_{2}^{+}-\mathrm{CH}_{3} \mathrm{OH}$. The elimination of methanol involves the methoxy portion of the reactant and one acidic hydrogen from the analyte. To determine the site of reaction, CAD studies were performed on the $[M+13]^{+}$ion as well as its precursor $[M+45]^{+}$. The results from the collision-activated dissociation of the $[\mathrm{M}+45]^{+}$and $[\mathrm{M}+13]^{+}$ions are listed in Table 2. An example of a CAD spectrum is shown in Figure 3 for $[M+45]^{+}$. The $[M+45]^{+}$adduct dissociates by loss of water, an expected elimination of methanol to form $[\mathrm{M}+13]^{+}$, and various other fragments discussed in subsequent text. The $[\mathrm{M}+13]^{+}$ion dissociates predominantly by elimination of formaldehyde $(30 \mathrm{u})$ and by loss of methyl formate $(60 \mathrm{u})$, as well as several minor pathways.

To allow speculation about the structure of some of these fragments, perdeuterated dimethyl ether was used as a reagent. The $\left[\mathrm{M}+\mathrm{CD}_{3} \mathrm{OCD}_{2}^{+}\right]$adduct was isolated and collisionally activated. The CAD spectrum of $\left[\mathrm{M}+\mathrm{CD}_{3} \mathrm{OCD}_{2}^{+}\right]$indicates two deuteriums present in the methylene substitution product that give an ion at $369 \mathrm{u}$, net $\left[\mathrm{M}+\mathrm{CD}_{3} \mathrm{OCD}_{2}^{+}-\mathrm{CD}_{3} \mathrm{OH}\right]$, and no deuteriums present in the ion at $337 \mathrm{u}$. Scheme I has been proposed to explain these observations. The initial addition of the $\mathrm{CD}_{3} \mathrm{OCD}_{2}^{+}$cation on the alcoholic oxygen followed by the loss of $\mathrm{CD}_{3} \mathrm{OH}$ will give an ion at $369 \mathrm{u}$ with two deuteriums present. A subsequent loss of $\mathrm{CD}_{2} \mathrm{O}$ from this site will result in a product with no deuteriums present $(337 \mathrm{u})$. The consecutive nature of this reaction is confirmed by activation of the 367-u ion as well as MS $^{3}$ experiments where the 367-u fragment ion generated from the initial activation of
Table 2. Dimethyl ether CAD products

\begin{tabular}{|c|c|c|}
\hline Precursor ion & Product ion & Relative percent \\
\hline $399^{+}$ & {$\left[\mathrm{M}+45-\mathrm{H}_{2} \mathrm{O}\right]^{+}$} & $\leq 5$ \\
\hline \multirow[t]{9}{*}[M+45]{$^{+}$} & {$[M+13]^{+}$} & 20 \\
\hline & $339^{+}$ & 10 \\
\hline & $337^{+}$ & 10 \\
\hline & $297^{+}$ & 10 \\
\hline & $265^{+}$ & $\leq 5$ \\
\hline & $226^{+}$ & 10 \\
\hline & $224^{+}$ & 10 \\
\hline & $212^{+}$ & 10 \\
\hline & $188^{+}$ & 10 \\
\hline $381^{+}$ & $352^{+}$ & 15 \\
\hline \multirow[t]{5}{*}[\mathrm{M}+45-\mathrm{H}_{2}\mathrm{O}]{$^{+}$} & $349^{+}$ & 35 \\
\hline & $338^{+}$ & 20 \\
\hline & $325^{+}$ & $\leq 5$ \\
\hline & $320^{+}$ & 35 \\
\hline & $306^{+}$ & 20 \\
\hline $367^{+}$ & $339^{+}$ & $\leq 5$ \\
\hline \multirow[t]{5}{*}[M+13]{$^{+}$} & $337^{+}$ & 45 \\
\hline & $307^{+}$ & 25 \\
\hline & $294^{+}$ & $\leq 5$ \\
\hline & $279^{+}$ & $\leq 5$ \\
\hline & $265^{+}$ & 15 \\
\hline $355^{+}$ & $337^{+}$ & 45 \\
\hline \multirow[t]{7}{*}[\mathrm{M}+\mathrm{H}]{$^{+}$} & $308^{+}$ & $\leq 5$ \\
\hline & $295^{+}$ & 10 \\
\hline & $294^{+}$ & $\leq 5$ \\
\hline & $266^{+}$ & $\leq 5$ \\
\hline & $252^{+}$ & $\leq 5$ \\
\hline & $212^{+}$ & 20 \\
\hline & $152^{+}$ & $\leq 5$ \\
\hline
\end{tabular}

$[M+45]^{+}$subsequently was activated and gave the ion at $337 \mathrm{u}$.

The $\mathrm{CD}_{3} \mathrm{OCD}_{2}^{+}$results also suggest that methylene substitution occurs at more than one location. Activation of the deuterated methylene-substituted product, $\left[\mathrm{M}+\mathrm{CD}_{3} \mathrm{OCD}_{2}^{+}-\mathrm{CD}_{3} \mathrm{OH}\right]$, indicates the $307-\mathrm{u}$ ion and the 265-u ion shift to 309 and $267 \mathrm{u}$, respectively. It is proposed that the losses of methyl formate and ketene from the nondeuterated $[\mathrm{M}+13]^{+}$ion give the $307-$ and $265-u$ ions. Scheme II is proposed to explain

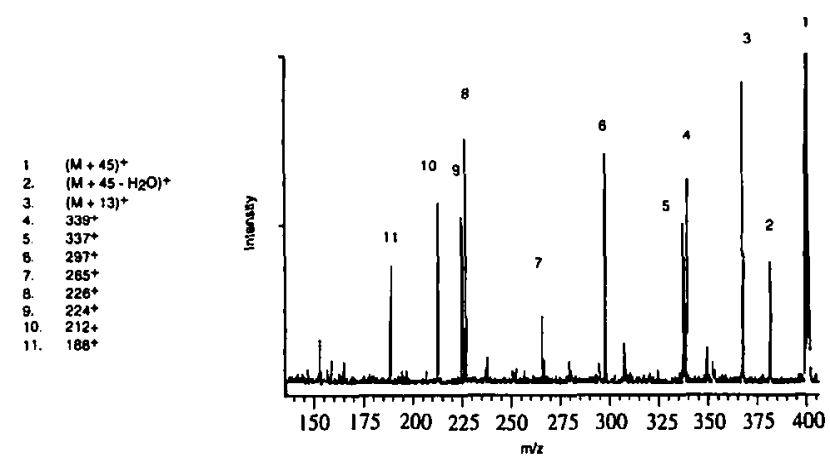

Figure 3. Collision-activated dissociation of $[M+45]^{+}$from dimethyl ether and vincamine. 


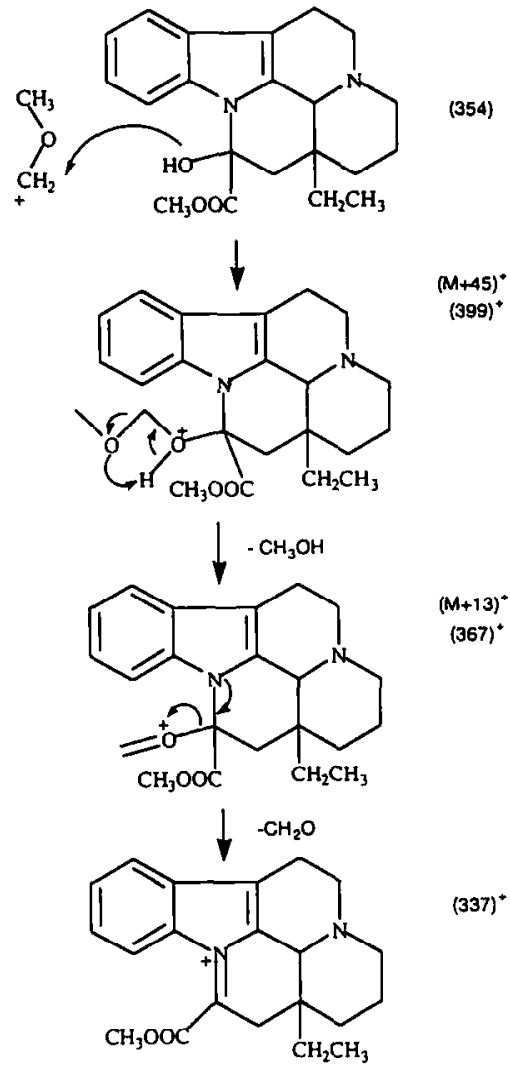

Scheme I. Methylene substitution of vincamine and formation of the 337-u ion.

this phenomenon by having an alternate site of methylene substitution somewhere on the phenyl ring. The exact site of attachment of the $\mathrm{CH}_{3} \mathrm{OCH}_{2}^{+}$ion is unknown, and only one situation that shows attachment at the 9 phenyl position is outlined in Scheme II. For the $[M+45]^{+}$products that result from phenyl attack, the consecutive losses of methyl formate and ketene occur remote from the charged site. The first $[\mathrm{M}+13]^{+}$ product shown in Scheme I fails to account for this behavior because although the loss of methyl formate may occur easily, there is no viable pathway for the subsequent elimination of ketene because the methylene substituent blocks the remaining oxygen. The charge-remote losses of methyl formate and ketene shown in Scheme II for the $[\mathrm{M}+13]^{+}$ion also can be used to explain the same losses observed directly in the CAD spectrum of the $[\mathrm{M}+45]^{+}$adduct. We speculate that the fragment ions at 339 and $297 \mathrm{u}$, respectively, stem from the remote loss of methyl formate ( 60 $\mathrm{u}$ ), that, in conjunction with ketene, totals a net loss of $102 \mathrm{u}$ from $[\mathrm{M}+45]^{+}$.

More evidence for the possibility of the remote loss of methyl formate is obtained from further inspection of the CAD spectrum of $\left[\mathrm{M}+\mathrm{CD}_{3} \mathrm{OCD}_{2}^{+}\right]$. The fragment ion noted at $339 \mathrm{u}$ in the $\mathrm{CAD}$ spectrum of $\left[\mathrm{M}+\mathrm{CH}_{3} \mathrm{OCH}_{2}^{+}\right]$shifts to $344 \mathrm{u}$ in the $\mathrm{CAD}$ spectrum of $\left[\mathrm{M}+\mathrm{CD}_{3} \mathrm{OCD}_{2}^{+}\right]$, which indicates retention of all five deuterium ions in the fragment ion. However, it
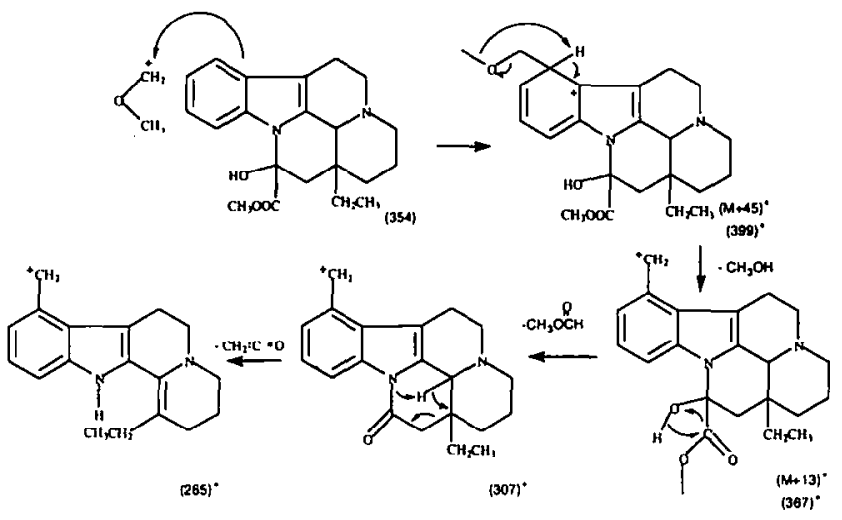

Scheme II. Methylene substitution of vincamine on the phenyl ring followed by losses of methyl formate and ketene.

should be noted that methyl formate also can be lost from the $[M+45]^{+}$structure shown in Scheme III, in which the extra hydrogen on the phenyl ring adjacent to the charged site is transferred to the ester substituent, which thereby eliminates $\mathrm{HCOOCH}_{3}$.

The ion at $381 \mathrm{u}$ in Table 2 from the CAD of the $[\mathrm{M}+45]^{+}$adduct indicates a loss of water. Upon closer inspection, this ion also was found in very low abundance $(<2 \%)$ in the chemical ionization spectrum of vincamine. $\mathrm{CAD}$ of the $\left[\mathrm{M}+\mathrm{CD}_{3} \mathrm{OCD}_{2}^{+}\right]$ adduct shows loss of $\mathrm{H}_{2} \mathrm{O}$ with no loss of $\mathrm{HDO}$, and can be explained by the mechanism proposed in Scheme III. Addition of the methoxymethylene cation

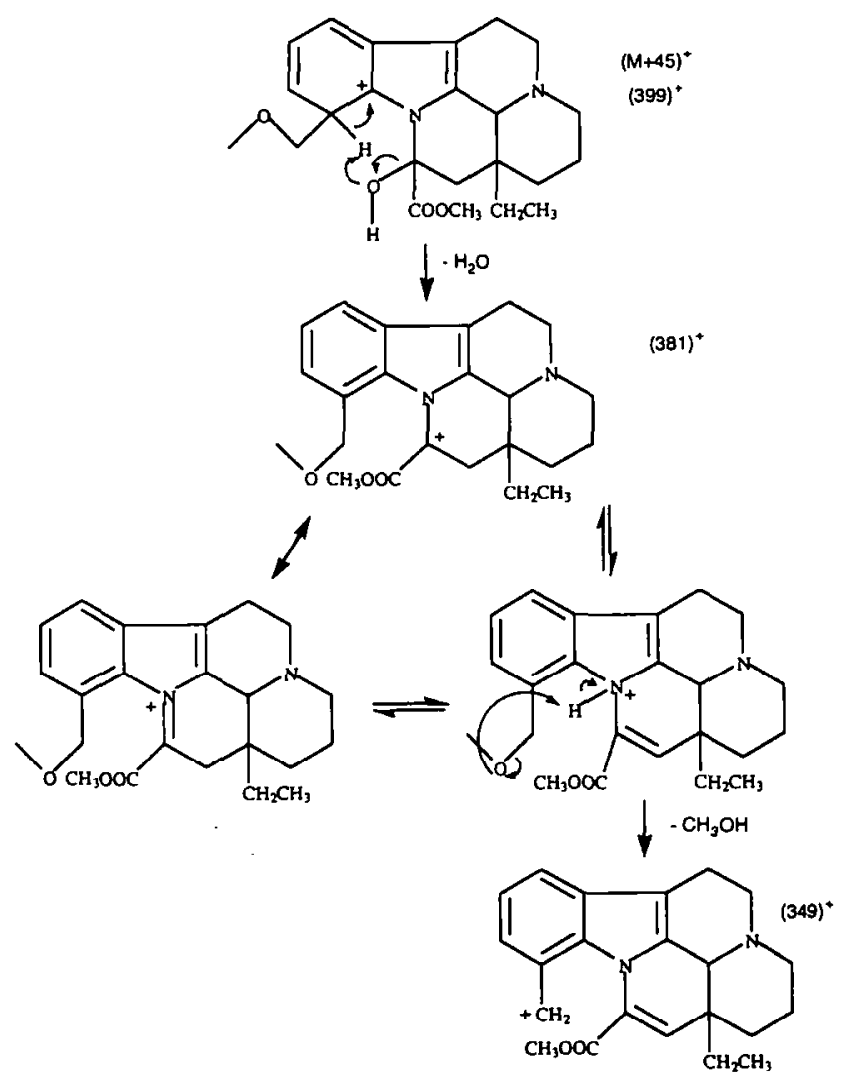

Scheme III. Loss of water from $[\mathrm{M}+45]^{+}$and formation of the 349-u ion. 
on the 12 phenyl position possibly can promote intramolecular proton transfer from the phenyl ring to the hydroxyl oxygen. A model compound, eburnamonine, also was studied to further investigate this dehydration reaction and can be compared to vincamine in Figure 1. This compound is similar to vincamine with the exception that it has a carbonyl group in place of the hydroxyl and the ester groups. Upon activation of the $[M+45]^{+}$eburnamonine adduct, no loss of water was observed, which supports the hypothesis that the hydroxyl group is necessary for the dehydration step to occur.

In the CAD spectrum of $\left[\mathrm{M}+\mathrm{CD}_{3} \mathrm{OCD}_{2}^{+}-\mathrm{H}_{2} \mathrm{O}\right]$, a loss of $\mathrm{CD}_{3} \mathrm{OH}$ was found and also is explained in this mechanism. This fragmentation process involves the methoxyl portion of the $\mathrm{CH}_{3} \mathrm{OCH}_{2}^{+}$reactant that extracts a proton from the pyrrole nitrogen, as shown in Scheme III.

In summary, the CAD results and labeling experiments support several different pathways for the reactions of $\mathrm{CH}_{3} \mathrm{OCH}_{2}^{+}$ions with vincamine. The favored sites of attack appear to be the hydroxyl oxygen and some or all of the phenyl ring positions. Remote site fragmentation processes may occur from the $[\mathrm{M}+45]^{+}$ and $[M+13]^{+}$products that specifically stem from the phenyl substitution mechanisms.

\section{Reactions with 2-Methoxyethanol Ions}

After electron ionization, 2-methoxyethanol produces ions at 45, 59, 77, and $89 u$ [21]. The 59- and 77-u ions were shown to be of no analytical use, whereas the 45-u ion was shown to be the same methoxymethylene cation produced by dimethyl ether [21]. The $\left(\mathrm{CH}_{3} \mathrm{OCH}_{2} \mathrm{CH}_{2} \mathrm{OCH}_{2}\right)^{+}$ion at $89 \mathrm{u}-$ the product of the reaction between the methoxymethylene cation and neutral 2-methoxyethanol-has demonstrated selectivity toward amines as a result of its ability to engage in hydrogen bonding that involves the methoxy tail of the reactant ion and any acidic hydrogen in the analyte [21]. Typically, it produces $[M+89]^{+}$as well as $[\mathrm{M}+13]^{+}$adducts in the chemical ionization spectrum.

In a 20 -ms period, several abundant vincamine products were observed upon reactions of the $\left(\mathrm{CH}_{3} \mathrm{OCH}_{2} \mathrm{CH}_{2} \mathrm{OCH}_{2}\right)^{+}$ions. As shown in Table 1, the $[\mathrm{M}+89]^{+}$and $[\mathrm{M}+13]^{+}$adducts along with two ions at lower masses are the main products. The $[\mathrm{M}+13]^{+}$methylene-substituted product at $367 \mathrm{u}$ is the most intense ion in the spectrum. This ion along with the characteristic $[\mathrm{M}+89]^{+}$adduct provides a way to identify that vincamine is a nitrogen-containing compound and determine its molecular weight.

To further probe the site of adduct formation, CAD was employed on the $[M+89]^{+}$and $[M+13]^{+}$ions. The results for the activation of these ions are given in Table 3 and show many similarities to the results for the activation of $[M+45]^{+}$and $[M+13]^{+}$for
Table 3. 2-Methoxyethanol CAD products

\begin{tabular}{ccc}
\hline Precursor ion & Product ion & Relative percent \\
\hline \hline $443^{+}$ & {$[\mathrm{M}+13]^{+}$} & 60 \\
{$[\mathrm{M}+89]^{+}$} & $341^{+}$ & 10 \\
& $339^{+}$ & $\leq 5$ \\
& $337^{+}$ & 10 \\
& $307^{+}$ & $\leq 5$ \\
& $265^{+}$ & 10 \\
& $226^{+}$ & $\leq 5$ \\
& $224^{+}$ & $\leq 5$ \\
$425^{+}$ & $396^{+}$ & 15 \\
& $382^{+}$ & 20 \\
& $368^{+}$ & 10 \\
& $349^{+}$ & 35 \\
& $320^{+}$ & 15 \\
$367^{+}$ & $339^{+}$ & 15 \\
{$[\mathrm{M}+13]^{+}$} & $317^{+}$ & 10 \\
& $307^{+}$ & 20 \\
& $279^{+}$ & $\leq 5$ \\
& $278^{+}$ & $\leq 5$ \\
& $271^{+}$ & 10 \\
& $265^{+}$ & 30 \\
& $183^{+}$ & 10 \\
& &
\end{tabular}

dimethyl ether in Table 2. The $[\mathrm{M}+89]^{+}$from 2methoxyethanol and the $[\mathrm{M}+45]^{+}$from dimethyl ether show nearly analogous fragmentation pathways, which include elimination of methyl formate with ketene, formation of $[M+13]^{+}$, formation of $337 \mathrm{u}$, and lower mass fragments. These parallel results suggest that the mechanisms for formation and fragmentation of the $[\mathrm{M}+45]^{+}$and $[\mathrm{M}+89]^{+}$ions might be similar. It should be noted, however, that the fragment ion at $339 \mathrm{u}$ in Table 2 for $[\mathrm{M}+45]^{+}$cannot be the same species as the fragment ion at $339 \mathrm{u}$ in Table 3 for $[\mathrm{M}+89]^{+}$. As discussed previously, the elimination of methyl formate from $[M+45]^{+}$was likely a chargeremote process that did not involve the attached $\mathrm{CH}_{3} \mathrm{OCH}_{2}^{+}$group. Thus, the analogous charge-remote process for $[\mathrm{M}+89]^{+}$would result in a loss of $60 \mathrm{u}$ and a fragment ion at $383 \mathrm{u}$. This process is not observed. The ion at $339 \mathrm{u}$ therefore arises from a different process, as discussed in following text and shown in Scheme IV.

Upon further analysis it is also apparent that the $[\mathrm{M}+13]^{+}$ion formed from the 2-methoxyethanol reactions is not identical to the $[\mathrm{M}+13]^{+}$ion generated from the dimethyl ether reactions. The CAD spectrum from the $[M+13]^{+}$product of 2-methoxyethanol shows a predominant loss of $28 \mathrm{u}$ to give an ion at 339 $\mathrm{u}$, but shows no dissociation to $337 \mathrm{u}$ (refer to Table 3). The $[M+13]^{+}$product from dimethyl ether fragments extensively to $337 \mathrm{u}$ and shows little elimination of 28 $\mathrm{u}$ (refer to Table 2). To further probe this difference, an experiment that used deuterated reagents was devised. 


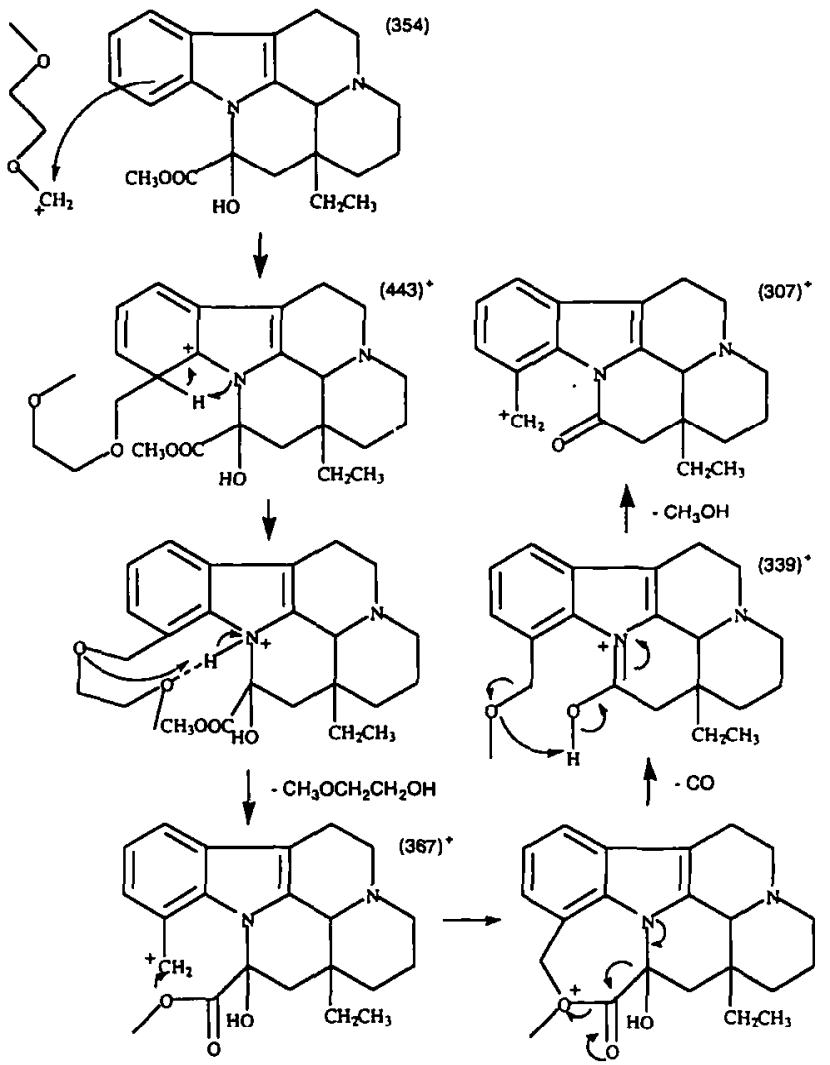

Scheme IV. Stabilization of the 89-u ion from 2-methoxyethanol and formation of the 339- and 307-u ions.

Perdeuterated dimethyl ether and 2-methoxyethanol both were introduced into the ion trap. Electron ionization was used to generate $\mathrm{CD}_{3} \mathrm{OCD}{ }_{2}^{+}$, which then reacted with neutral 2-methoxyethanol to give an ion that contained two deuteriums at $91 \mathrm{u}\left[\left(\mathrm{CH}_{3} \mathrm{OCH}_{2} \mathrm{CH}_{2} \mathrm{OCD}_{2}\right)^{+}\right]$rather than $89 \mathrm{u}$ $\left[\left(\mathrm{CH}_{3} \mathrm{OCH}_{2} \mathrm{CH}_{2} \mathrm{OCH}_{2}\right)^{+}\right]$. Product ions for vincamine were formed at $445 \mathrm{u}\left([\mathrm{M}+91]^{+}\right)$and $369 \mathrm{u}([\mathrm{M}+$ $\left.\mathrm{CH}_{3} \mathrm{OCH}_{2} \mathrm{CH}_{2} \mathrm{OCD}_{2}-\mathrm{CH}_{3} \mathrm{OCH}_{2} \mathrm{CH}_{2} \mathrm{OH}\right]^{+}$) in this manner and were activated.

The results show that the $337-\mathrm{u}$ ion in the CAD spectrum of $[M+91]^{+}$shifts to $339 u$, which indicates that both deuteriums stay with the product ion during dissociation. A mechanism to explain these observations is illustrated in Scheme IV, which shows addition of $\mathrm{CH}_{3} \mathrm{OCH}_{2} \mathrm{CH}_{2} \mathrm{OCH}_{2}^{+}$at the 12 phenyl position. An intramolecular proton transfer to the nitrogen then allows a hydrogen-bonding interaction to occur between the methoxy oxygen and the ammonium site that stabilizes the adduct. The adduct then proceeds to lose neutral 2-methoxyethanol and form a sevenmembered cyclic structure. From this structure, subsequent losses of carbon monoxide to form $339 \mathrm{u}$ and methanol to form $307 \mathrm{u}$ occur. Further evidence for this specific site of attack is found upon closer inspection of the CAD results for the dimethyl ether products. In Scheme III, it was assumed that addition of
$\mathrm{CH}_{3} \mathrm{OCH}_{2}^{+}$occurred at the 12 phenyl position to permit loss of water and subsequent elimination of $\mathrm{CH}_{3} \mathrm{OH}$. Addition of $\mathrm{CH}_{3} \mathrm{OCH}_{2}^{+}$to the 12 phenyl position also would allow formation of $[\mathrm{M}+13]^{+}$ions in which the methylene substitution occurs at the 12 phenyl position, which results in the same $[\mathrm{M}+13]^{+}$ structure shown at the bottom of Scheme IV. In Table 2 , a small percentage of $\mathrm{CO}$ loss from $[\mathrm{M}+13]^{+}$is observed (formation of the fragment ion at $339 \mathrm{u}$ ), which indicates that a mechanism for $\mathrm{CO}$ loss similar to Scheme IV occurs, but to a smaller extent. The reason for the smaller percentage can be explained by the special ability of the $\mathrm{CH}_{3} \mathrm{OCH}_{2} \mathrm{CH}_{2} \mathrm{OCH}_{2}^{+}$ion to hydrogen-bond with its methoxy tail and to stabilize the $[\mathrm{M}+89]^{+}$structure. Because the methoxymethylene ion cannot provide stabilization in the same manner due to lack of a second hydrogen-bond-accepting oxygen atom, addition at the 12 phenyl position is less favored. The enhanced stabilization and subsequent cyclized structure for $[M+89]^{+}$and $[M+13]^{+}$reasonably justify why the percentage of the $[M+13]^{+}$ product is so much greater for the 2-methoxyethanol $\mathrm{CI}$ distribution relative to the dimethyl ether $\mathrm{CI}$ product distribution in Table 1 . In addition, CAD of the $[\mathrm{M}+13]^{+}$ion from 2-methoxyethanol, found in Table 3 , fails to give a product that corresponds to the elimination of formaldehyde. This suggests that attack of the $\mathrm{CH}_{3} \mathrm{OCH}_{2} \mathrm{CH}_{2} \mathrm{OCH}_{2}^{+}$ion at the hydroxyl oxygen is not favored.

Another loss to note in the CAD spectrum of $[\mathrm{M}+89]^{+}$is elimination of $102 \mathrm{u}$ to give a $341-\mathrm{u}$ ion. This is likely to be similar to the mechanism proposed for the $[M+45]^{+}$ions that involves remote loss of methyl formate and ketene with the structure of the rest of the ion staying intact. The ion at $265 \mathrm{u}$ from the loss of methyl formate and ketene also is present in the CAD spectrum of $[M+13]^{+}$.

As with dimethyl ether, a loss of water $([\mathrm{M}+89-$ $\mathrm{H}_{2} \mathrm{O}^{+}$) is observed in the $\mathrm{CI}$ spectrum for 2methoxyethanol, but this loss does not occur in the CAD spectrum of $[M+89]^{+}$, probably because other fragmentation processes are favored more highly. Upon closer inspection of the CAD spectra for $[\mathrm{M}+89-$ $\left.\mathrm{H}_{2} \mathrm{O}\right]^{+}$and $\left[\mathrm{M}+45-\mathrm{H}_{2} \mathrm{O}\right]^{+}$, neutral losses and fragment ions from the $\left[\mathrm{M}+89-\mathrm{H}_{2} \mathrm{O}\right]^{+}$product are similar to those seen for the $\left[\mathrm{M}+45-\mathrm{H}_{2} \mathrm{O}\right]^{+}$ dimethyl ether adduct, which include loss of 29,43 , and 57 as well as formation of ions at 349 and $320 u$. These similarities suggest analogous ion structures.

In summary, attachment of $\mathrm{CH}_{3} \mathrm{OCH}_{2} \mathrm{CH}_{2} \mathrm{OCH}_{2}^{+}$ to the hydroxyl oxygen of vincamine appears much less favorable than was noted for $\mathrm{CH}_{3} \mathrm{OCH}_{2}^{+}$, presumably due to the special hydrogen-bonding capabilities of the $\mathrm{CH}_{3} \mathrm{OCH}_{2} \mathrm{CH}_{2} \mathrm{OCH}_{2}^{+}$ion, which enhances its attachment at the 12 phenyl site. However, certain fragmentation processes, which include those supported as charge-remote pathways, appear analogous in some of these product ions. 


\section{Reactions with Vinyl Methyl Ether and Acetone Ions}

Acetone forms a number of ions upon electron ionization that include one at $43 \mathrm{u}$. Previous studies have shown the structure of this ion to be the acetyl ion [23]. Vinyl methyl ether also forms a 43-u ion from electron ionization, but, to the best of our knowledge, the structure of this ion has never been characterized fully. However, the structure of the 43-u ion from a related compound, vinyl ethyl ether, has been shown to be the acetyl ion as well [23].

The 43-u ion from vinyl methyl ether reacted in 20 ms with vincamine to give reasonably abundant product intensities. The acetone chemical ionization reactions, however, did not give sufficient total product ion intensities to be deemed acceptable. Table 1 indicates that the $\mathrm{CI}$ products from these reactions are very similar. The $[\mathrm{M}+43]^{+}$ion located at $397 \mathrm{u}$ is typical of the acetyl ion attachment and is useful for molecular weight determinations. The only differences are the presence of the 354- and 353-u ions in the vinyl methyl ether spectrum. Because the total product ion intensity in the acetone chemical ionization spectrum was so low, it is possible that these ions are formed, but not detected due to their low intensities.

CAD was performed on the $[M+43]^{+}$ions from vinyl methyl ether and acetone, and the resulting product intensities are located in Tables 4 and 5, respectively. Again, with the exception of a few ions of low intensity, the dissociation spectra are very similar. Because vinyl ethyl ether forms the acetyl ion and because the evidence here also supports the formation of this ion, it will be assumed that the 43-u ion from vinyl methyl ether assumes the acetyl structure and the results of these two reagents hereafter will be discussed together.

The formation of the 355-u ion in both the CI spectrum and in the CAD spectrum of the $[\mathrm{M}+43]^{+}$ion results from the elimination of ketene from the [M + $\left.\mathrm{CH}_{3} \mathrm{CO}^{+}\right]$ion. The process was confirmed by use of perdeuterated acetone to generate $\left[\mathrm{M}+\mathrm{CD}_{3} \mathrm{CO}^{+}\right]$ ions. A mechanism is proposed in Scheme $\mathrm{V}$ that indicates addition of $\mathrm{CH}_{3} \mathrm{CO}^{+}$to the nitrogen followed by the loss of ketene. A stepwise mechanism for the subsequent loss of water also is shown in Scheme $\mathrm{V}$. However, it is possible that the acetyl ion may attach directly to the hydroxyl oxygen to form [M + $43]^{+}$, and then elimination of acetic acid might occur directly to give $337 \mathrm{u}$.

Also present in the CI spectrum and the CAD spectrum of $[\mathrm{M}+43]^{+}$is an ion that corresponds to dehydration of the $[M+43]^{+}$species. Initially, it was thought that this ion formed in a similar manner to the ion already described in the dimethyl ether and 2methoxyethanol CI-CAD spectra found in Scheme III. That is, $\mathrm{CH}_{3} \mathrm{CO}^{+}$could attach to the phenyl ring and then the hydroxyl group could extract the extra hydro-
Table 4. Vinyl methyl ether CAD products

\begin{tabular}{|c|c|c|}
\hline Precursor ion & Product ion & Relative percent \\
\hline $397^{+}$ & {$\left[\mathrm{M}+43-\mathrm{H}_{2} \mathrm{O}\right]^{+}$} & 10 \\
\hline \multirow[t]{7}{*}[M+43]{$^{+}$} & {$[\mathrm{M}+\mathrm{H}]^{+}$} & 20 \\
\hline & $337^{+}$ & 15 \\
\hline & $308^{+}$ & $\leq 5$ \\
\hline & $295^{+}$ & 10 \\
\hline & $253^{+}$ & 20 \\
\hline & $212^{+}$ & $\leq 5$ \\
\hline & $186^{+}$ & 10 \\
\hline $379^{+}$ & $347^{+}$ & 15 \\
\hline \multirow[t]{9}{*}[\mathrm{M}+43-\mathrm{H}_{2}\mathrm{O}]{$^{+}$} & $337^{+}$ & 10 \\
\hline & $319^{+}$ & 40 \\
\hline & $308^{+}$ & $\leq 5$ \\
\hline & $305^{+}$ & $\leq 5$ \\
\hline & $291^{+}$ & $\leq \mathbf{5}$ \\
\hline & $277^{+}$ & $\leq 5$ \\
\hline & $260^{+}$ & $\leq 5$ \\
\hline & $253^{+}$ & $\leq 5$ \\
\hline & $211^{+}$ & $\leq 5$ \\
\hline $355^{+}$ & {$\left[\mathrm{M}+\mathrm{H}-\mathrm{H}_{2} \mathrm{O}\right]^{+}$} & 60 \\
\hline \multirow[t]{7}{*}[\mathrm{M}+\mathrm{H}]{$^{+}$} & $308^{+}$ & 10 \\
\hline & $295^{\prime}$ & $\leq 5$ \\
\hline & $294^{+}$ & 10 \\
\hline & $280^{+}$ & $\leq 5$ \\
\hline & $266^{+}$ & $\leq 5$ \\
\hline & $252^{+}$ & $\leq 5$ \\
\hline & $212^{+}$ & $\leq 5$ \\
\hline
\end{tabular}

gen on the ring, which results in the elimination of water. Upon reaction with the deuterated acetyl ion, a loss of $\mathrm{HDO}$, rather than $\mathrm{H}_{2} \mathrm{O}$, is apparent from the $\left[\mathrm{M}+\mathrm{CD}_{3} \mathrm{CO}^{+}\right]$ion and, therefore, the deuterium must originate from the acetyl substituent, not the phenyl ring. A mechanism that can account for these observations is a reversal of the sequence of steps shown in Scheme V. In this case, the dehydration step would precede the loss of ketene. The final product at $337 \mathrm{u}$ has the same structure as the one proposed in Scheme V.

The CAD spectrum of the $[\mathrm{M}+\mathrm{H}]^{+}$ion, given in Table 4, is almost identical to that of the $[\mathrm{M}+\mathrm{H}]^{+}$ion that results from the protonation of vincamine by protonated dimethyl ether. Therefore, it is probable that these protonated structures are similar.

Table 5. Acetone CAD products

\begin{tabular}{ccc}
\hline Precursor ion & Product ion & Relative percent \\
\hline \hline $397^{+}$ & {$\left[\mathrm{M}+43-\mathrm{H}_{2} \mathrm{O}\right]^{+}$} & 25 \\
{$[\mathrm{M}+43]^{+ \text {a }}$} & {$[\mathrm{M}+\mathrm{H}]^{+}$} & 25 \\
& $337^{+}$ & 15 \\
& $295^{+}$ & 10 \\
& $253^{+}$ & 25
\end{tabular}

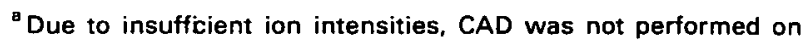
other precursors.
} 


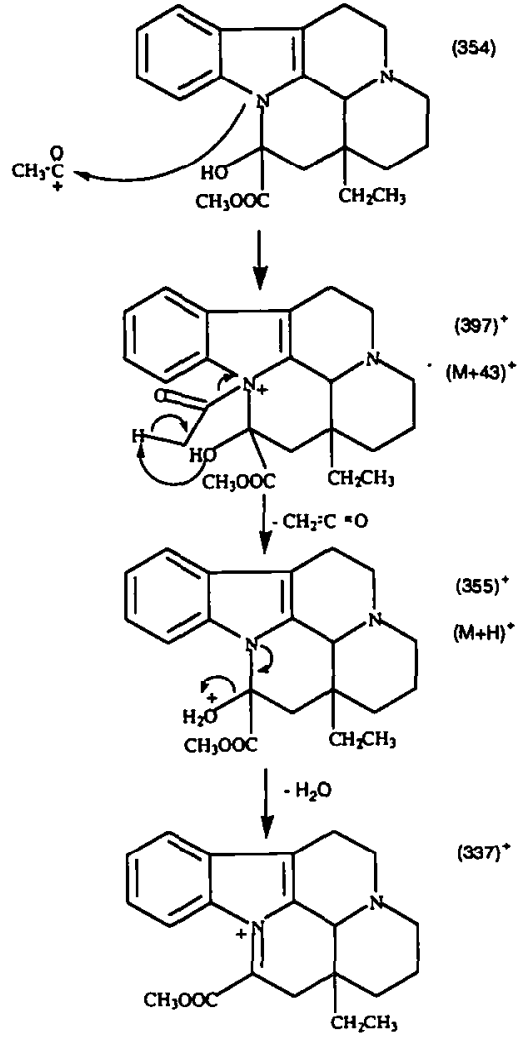

Scheme V. Acetyl addition followed by loss of ketene to give $[\mathrm{M}+\mathrm{H}]^{+}$, followed by loss of water.

\section{Reactions of a Structural Isomer: Corynanthine}

Corynanthine is an isomeric alkaloid of vincamine in which the hydroxyl and ester groups are remote from the pyrrole and phenyl rings (Figure 1). Reactions of dimethyl ether ions and 2-methoxyethanol ions with corynanthine were examined to evaluate the importance of the locations of the hydroxyl and ester groups and the nature of the pyrrole nitrogen on the reactivity of the molecule. Upon reaction with dimethyl ether ions, corynanthine forms abundant $[\mathrm{M}+\mathrm{H}]^{+}$and $\left[\mathrm{M}+\mathrm{CH}_{3} \mathrm{OCH}_{2}^{+}\right]$ions, but only a minor amount of $[\mathrm{M}+13]^{+}$products $(<1 \%)$. Likewise, upon reaction with $\mathrm{CH}_{3} \mathrm{OCH}_{2} \mathrm{CH}_{2} \mathrm{OCH}_{2}^{+}$from 2-methoxyethanol, corynanthine forms some $[\mathrm{M}+\mathrm{H}]^{+}$and predominantly $[M+89]^{+}$ions, but no $[M+13]^{+}$products. Thus, the formation of $[M+13]^{+}$ions is highly disfavored for corynanthine relative to vincamine, especially for the reactions with 2-methoxyethanol ions. The difference in product distributions for vincamine and corynanthine may be explained by several structural differences. First, it suggests that the distance of the hydroxyl and ester groups from the indole ring system has a large impact on the efficiency of the reaction that leads to $[M+13]^{+}$ions. Moreover, corynanthine has a secondary indole nitrogen, as opposed to the tertiary indole nitrogen that was found in vincamine. Secondary nitrogen atoms are extremely nucleophilic and are known to promote the attachment of
$\mathrm{CH}_{3} \mathrm{OCH}_{2}^{+}$ions [31]. Thus, the unblocked indole nitrogen atom in corynanthine may favor rapid formation of an entirely new type of $[\mathrm{M}+45]^{+}$structure (and likewise $[\mathrm{M}+89]^{+}$structure)-one which does not favor dissociation by elimination of $\mathrm{CH}_{3} \mathrm{OH}$ to form $[M+13]^{+}$ions.

To probe the nature of the resulting $\left[\mathrm{M}+\mathrm{H}^{+}\right.$, $\left[\mathrm{M}+\mathrm{CH}_{3} \mathrm{OCH}_{2}^{+}\right]$, and $\left[\mathrm{M}+\mathrm{CH}_{3} \mathrm{OCH}_{2} \mathrm{CH}_{2} \mathrm{OCH}_{2}^{+}\right]$ ions, $\mathrm{CAD}$ was performed. In contrast to protonated vincamine, protonated corynanthine dissociates only by two pathways, which results in formation of ions at 212 and $224 \mathrm{u}$. Dehydration does not occur at all. Structures for the ions at 212 and $224 \mathrm{u}$ are proposed in Scheme VI, and they both stem from elimination of the indole ring portion. Unlike the CAD patterns summarized in Tables 2 and 3 for vincamine, neither the $\left[\mathrm{M}+\mathrm{CH}_{3} \mathrm{OCH}_{2}^{+}\right]$nor $\left[\mathrm{M}+\mathrm{CH}_{3} \mathrm{OCH}_{2} \mathrm{CH}_{2} \mathrm{OCH}_{2}^{+}\right]$ ions dissociate to $[\mathrm{M}+13]^{+}$to any considerable extent. Instead, the $[\mathrm{M}+45]^{+}$ion dissociates to the same types of fragments that are noted for dissociation of the $[\mathrm{M}+\mathrm{H}]^{+}$corynanthine ion. The $[\mathrm{M}+45]^{+}$ion dissociates to ions at 212 and $224 \mathrm{u}$, as shown in Scheme VI, and an ion at $256 \mathrm{u}$, which likely represents the attachment of $\mathrm{CH}_{3} \mathrm{OCH}_{2}^{+}$in place of a hydrogen in the 212-u ion. The other major fragment is observed at $188 \mathrm{u}$, and likely represents the attachment of the $\mathrm{CH}_{3} \mathrm{OCH}_{2}^{+}$unit to the indole nitrogen, as shown in Scheme VI. The $\mathrm{CH}_{3} \mathrm{OCH}_{2}^{+}$unit remains intact and does not promote any unusual rearrangements or interactions of the methoxy tail with other parts of corynanthine.

The $[\mathrm{M}+89]^{+}$ion dissociates in analogous ways to the $[\mathrm{M}+45]^{+}$ion, which includes formation of $224 \mathrm{u}$. Instead of the ion at $188 \mathrm{u}$ seen for dissociation of $[\mathrm{M}+45]^{+}$, an analogous ion at $232 \mathrm{u}$ is observed in which $\mathrm{CH}_{3} \mathrm{OCH}_{2} \mathrm{CH}_{2} \mathrm{OCH}_{2}^{+}$presumably replaces $\mathrm{CH}_{3} \mathrm{OCH}_{2}^{+}$. Formation of $[\mathrm{M}+13]^{+}$ions from the

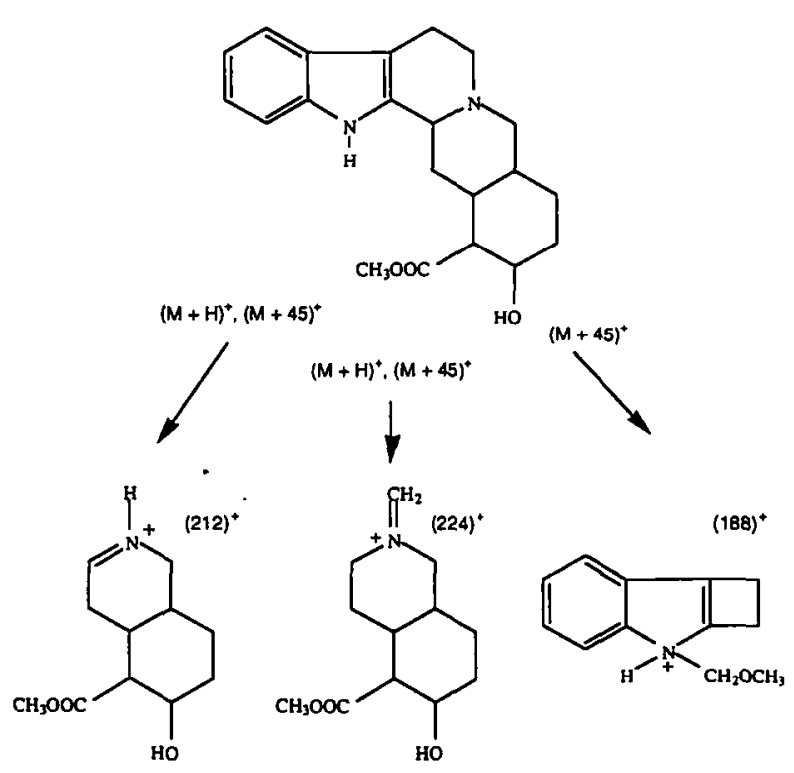

Scheme VI. Fragment ions from corynanthine. 
dissociation of $[M+89]^{+}$ions occurs only to a minor extent.

In general, these $\mathrm{CAD}$ patterns suggest that the reactions proposed for vincamine ions that involve intramolecular proton transfer and rearrangements are not favored. The two logical correlations are that the remote position of the hydroxyl and ester groups relative to the phenyl and pyrrole rings specifically retards those types of processes, and that the secondary indole nitrogen promotes the attachment of the $\mathrm{CH}_{3} \mathrm{OCH}_{2} \mathrm{CH}_{2} \mathrm{OCH}_{2}^{+}$or $\mathrm{CH}_{3} \mathrm{OCH}_{2}^{+}$at that nitrogen site rather than elsewhere on the phenyl ring or at the hydroxyl group.

\section{Derivatization of Vincamine and Limits of Detection}

Because of the extensive fragmentation of vincamine under electron ionization conditions [13, 17-19], which may restrict the detection limit at very low concentration levels, attention was focused on evaluation of the $\mathrm{CI}$ reactions for the quantitative determination of vincamine in various analytical applications. Dimethyl ether, 2-methoxyethanol, and vinyl methyl ether all gave CI spectra of vincamine that were thought to be acceptable for gas chromatography-mass spectrometry (GC/MS) work. Because dimethyl ether gives three products that have been well characterized for many types of compounds, it was chosen as the reagent for the GC/MS work.

GC separation has been done on underivatized vincamine $[15,16]$. In the present study, a GC program was devised for the underivatized compound to allow approximately $85 \%$ of vincamine to survive the injection and column conditions. The reactions of the eluted vincamine with dimethyl ether ions resulted in the same types of products already identified in Table 1. However, because some variable percentage of the vincamine decomposed in the injector or on the GC column, the use of underivatized vincamine was deemed unacceptable for quantitative analytical work. As an alternative, the trimethylsilyl (TMS) derivative of vincamine was made and gave uniformly reproducible GC/MS results. In the derivatization procedure, the hydroxyl group is converted to the trimethylsilyl ether group, and the molecular weight of $[\mathrm{M}+\mathrm{TMS}]$ is $426 \mathrm{u}$.

It was thus of interest to evaluate whether or not the TMS derivative underwent the same types of reactions with dimethyl ether ions as already described for the native vincamine, so that the dimethyl ether $\mathrm{CI}$ strategy could be applied as a quantitative analytical protocol. Upon reactions with dimethyl ether ions, the TMS derivative gave product ions at $337,367,381$, 427,439 , and $471 \mathrm{u}$. The $427-\mathrm{u}$ ion corresponds to $[\mathrm{M}+\mathrm{TMS}+\mathrm{H}]^{+}$, the $439-\mathrm{u}$ ion corresponds to $[\mathrm{M}+$ TMS +13$]^{+}$, and the 471-u ion corresponds to $[\mathrm{M}+$ TMS $\left.+\mathrm{CH}_{3} \mathrm{OCH}_{2}^{+}\right]$. The tandem mass spectrometry capability of the Saturn 4D benchtop ion trap was used to investigate these ions further.
The $\left[\mathrm{M}+\mathrm{TMS}+\mathrm{CH}_{3} \mathrm{OCH}_{2}^{+}\right]$adduct was activated and gave fragment ions at 439,381 , and $297 \mathrm{u}$. The 439-u ion corresponds to the methylene substitution process described earlier ( $\left[\mathrm{M}+\mathrm{TMS}+\mathrm{CH}_{3} \mathrm{OCH}_{2}^{+}-\right.$ $\left.\mathrm{CH}_{3} \mathrm{OH}\right]$ ). The 381-u ion is analogous to a dehydration product described earlier and corresponds to loss of $\left(\mathrm{CH}_{3}\right)_{3} \mathrm{SiOH}$ from the $\left[\mathrm{M}+\mathrm{TMS}+\mathrm{CH}_{3} \mathrm{OCH}_{2}^{+}\right]$ adduct in a mechanism similar to that in Scheme III in which a proton from the phenyl ring transfers to the $\left(\mathrm{CH}_{3}\right) \mathrm{SiO}$ functional group. The most abundant ions in the CAD spectrum of the $[\mathrm{M}+\mathrm{TMS}+\mathrm{H}]^{+}$ion were 337 and $367 \mathrm{u}$, which arise via loss of 90 and $60 \mathrm{u}$, respectively. The $367-\mathrm{u}$ ion can arise from consecutive elimination of methanol and $\mathrm{CO}$ or loss of methyl formate from the $[\mathrm{M}+\mathrm{TMS}+\mathrm{H}]^{+}$ion. The 337-u ion can form by a loss of $\left(\mathrm{CH}_{3}\right)_{3} \mathrm{SiOH}$ in a mechanism analogous to that proposed for the dehydration process of $[\mathrm{M}+\mathrm{H}]^{+}$.

Finally, the reactions of TMS-derivatized vincamine offer further evidence that there are several reactive sites in the nonderivatized compound. Because the hydroxyl oxygen is capped by the TMS group in the derivatized vincamine, attachment of $\mathrm{CH}_{3} \mathrm{OCH}_{2}^{+}$at the hydroxyl oxygen cannot ultimately lead to the methylene substitution process because there is no available acidic hydrogen for the required elimination of methanol. However, observation of the $[\mathrm{M}+$ TMS +13$]^{+}$ion in the CI product spectrum suggests that the methylene substitution process may proceed at the phenyl ring remote from the TMS group (as shown in the first few steps of Scheme II). Thus, all mechanisms proposed earlier for the $\left[\mathrm{M}+\mathrm{CH}_{3} \mathrm{OCH}_{2}^{+}\right]$ adducts in which attachment of $\mathrm{CH}_{3} \mathrm{OCH}_{2}^{+}$occurred at the hydroxyl group are inactive.

The limit of detection for the reactions of dimethyl ether ions with the derivatized form of vincamine was determined to be 100 parts per trillion (picograms per milliliter) based on summation of the ion intensity for the $\left[\mathrm{M}+\mathrm{TMS}+\mathrm{CH}_{3} \mathrm{OCH}_{2}^{+}\right],[\mathrm{M}+\mathrm{TMS}+\mathrm{H}]^{+}$, and the 337-u products. The limit of detection was established at a signal-to-noise ratio of 5 and with the retention time matched to within $2 \mathrm{~s}$. In the electron ionization mode, the detection limit was about three times higher, presumably because the ion current was divided among many fragmentation channels, which thus lowers the intensity of any single ion.

\section{Conclusions}

Of the four chemical ionization reagents studied, dimethyl ether, 2-methoxyethanol, and vinyl methyl ether demonstrated analytical utility with vincamine. The chemical ionization spectra of all reagents gave ions that are characteristic of the reagent, and the reagents are useful to determine molecular weight and to provide structural information about vincamine.

Reaction with the $\mathrm{CH}_{3} \mathrm{OCH}_{2}^{+}$ions from dimethyl ether gave the $\left[\mathrm{M}+\mathrm{CH}_{3} \mathrm{OCH}_{2}^{+}\right]$adduct, the $\left[\mathrm{M}+\mathrm{CH}_{3} \mathrm{OCH}_{2}^{+}-\mathrm{H}_{2} \mathrm{O}\right]$ ion, and the $[\mathrm{M}+13]^{+}$pro- 
duct. CAD spectra of these ions indicated that at least two sites of attachment for the methoxymethylene cation were present: the phenyl ring and the hydroxyl oxygen. The reaction of vincamine with the $\mathrm{CH}_{3} \mathrm{OCH}_{2} \mathrm{CH}_{2} \mathrm{OCH}_{2}^{+}$ion from 2-methoxyethanol produced the $[\mathrm{M}+13]^{+}$ion and the $[\mathrm{M}+89]^{+}$ion. It was proposed that due to the ability of the $\mathrm{CH}_{3} \mathrm{OCH}_{2} \mathrm{CH}_{2} \mathrm{OCH}_{2}^{+}$ion to undergo hydrogen bonding with an acidic hydrogen of vincamine, the addition to the phenyl ring occurred predominantly at the 12 phenyl position. The results show that charge-remote fragmentations were possible for some of the product ions. Also of interest was the number of dissociation mechanisms that required a intramolecular proton transfer. The reactions of vinyl methyl ether and acetone were identical, probably because the 43-u ions from both reagents assumed the acetyl conformation. The acetyl ion added to the pyrrole nitrogen to form $[\mathrm{M}+43]^{+}$, which then lost ketene to give protonated vincamine $\left([\mathrm{M}+\mathrm{H}]^{+}\right)$, or lost water to give the $[\mathrm{M}+$ $\left.43-\mathrm{H}_{2} \mathrm{O}\right]^{+}$ion.

The trimethylsilyl derivative of vincamine was synthesized for GC/MS experiments, and dimethyl ether was chosen as the chemical ionization reagent. This derivative was found to react in a similar manner to the nonderivatized compound. Addition of $\mathrm{CH}_{3} \mathrm{OCH}_{2}^{+}$ occurred on the phenyl ring, but due to the TMS group, no addition occurred on the alcoholic oxygen. The limit of detection for the technique was 100 parts per trillion.

\section{Acknowledgments}

This work was supported by the National Institutes of Health, the National Science Foundation, the Dreyfus Foundation, the Sloan Foundation, and the Welch Foundation.

\section{References}

1. Lounasmaa, M.; Tolvanen, A. In The Alkaloids, Vol. 42; Cordell, G. A., Ed.; Academic Press: New York, 1992; pp 1-116.

2. Dubruc, C.; Caqueret, H.; Bianchetti, G. J. Chromatogr. 1981, 204, 335-339.

3. Szepesi, G.; Gazdag, M. J. Chromatogr. 1981, 204, 341-348.

4. Pietta, P.; Rava, A.; Catenacci E. J. Chromatogr. 1981, 210, 149-153.
5. Perera, P.; Van Beek, T. A.; Verpoorte, R. J. Chromatogr. 1984, 285, 214-220.

6. Van Der Heijden, R.; Lamping, P. J.; Out, P. P.; Wijnsma, R.; Verpoorte, R. J. Chromatogr. 1987, 396, 287-295.

7. Bo, L. D.; Ceriani, G.; Broccali, F. J. Chromatogr. Biomed. Appl. 1992, 573, 158-162.

8. Hill, D. W.; Kind, A. J. I. Liquid Chromatogr. 1993, 16, 3941-3964.

9. Smyth, M. R. Analyst 1986, 111, 851-852.

10. Auriola, S.; Naaranlahti, T.; Kostiainen, R.; Lapinjoki, S. P. Biomed. and Environ. Mass Spectrom. 1990, 19, 609-612.

11. Bressolle, F.; Bres, J.; Brun, S. J. Chromatogr. 1979, 174, 421-433.

12. Lee, Y.-W.; Voyksner, R. D.; Fang, Q.-C.; Cook, C.-E.; Ito, C. E. J. Liquid Chromatogr. 1988, 11. 153-171.

13. Hoppen, H.-O.; Heuer, R.; Seidel, G. Biomed. Mass Spectrom. 1978, 5, 133-135.

14. Gazdag, M.; Mihályfi, K.; Szepesi, G. Fresenius' Z. Anal. Chem. 1981, 309, 105-108.

15. Kinsun, H.; Moulin, M. A. J. Chromatogr. 1977, 144, 123-126.

16. Michotte, Y.; Massart, D. L. J. Chromatogr., Biomed. Appl. 1985, 344, 367-371.

17. Budzikiewicz, H.; Djerassi, C.; Williams, D. H. Structure Elucidation of Natural Products by Mass Spectrometry, Vol. 1: The Alkaloids; Holden-Day: San Francisco, CA 1964; pp 60-76.

18. Czira, G.; Tamás, J.; Kalaus, G. Org. Mass Spectrom. 1984, 19 , 555-562.

19. Kovácik, V.; Kompis, I. Collect. Czech. Chem. Commun. 1969, 34, 2809-2018.

20. Vairamani, M.; Mirza, L'. A.; Srinivas, R. Mass Spectrom. Rev. 1990, 9, 235-258.

21. Alvarez, E. J.; Brodbelt, J. S. J. Mass Spectrom. 1995, 30, 625-631.

22. Wang, S.; Sah, Y.; Xu, S.; Pan, J. Anal. Chem. 1985, 57, 2283-2286.

23. Eberlin, M. N.; Majumdar, T. K.; Cooks, R. G. J. Am. Chem. Soc. 1992, 114, 2884-2896.

24. van Doorn, R.; Nibbering, N. M. M. Org. Mass Spectrom. 1978, $13,527-534$.

25. Brodbelt, J.; Liou, C.-C.; Donovan, T. Anal. Chem. 1991, 63, 1205-1209.

26. Donovan, T.; Liou, C.-C.; Brodbelt, J. I. Am. Soc. Mass Spectrom. 1992, 3, 39-46.

27. Keough, T. Anal. Chem. 1982, 54, 2540-25467.

28. Ferrer-Correia, A. J. V.; Jennings, K. R.; Sen Sharma, D. K. Org. Mass Spectrom. 1976, 11, 867-872.

29. Chai, R.; Harrison, A. G. Anal. Chem. 1981, 53, 34-37.

30. Ghaderi, S.; Kilkarni, P. S.; Ledford, E. B., Jr.; Wilkins C. L.; Gross, M. L. Anal. Chem. 1981, 53, 428-437.

31. Eichmann, E. S.; Brodbelt, J. S. J. Am. Soc. Mass Spectrom. 1993, 4, 230-241. 